\title{
Detection of MET mRNA in gastric cancer in situ. Comparison with immunohistochemistry and sandwich immunoassays
}

\author{
E Schmid ${ }^{1}$, M Klotz ${ }^{1}$, K Steiner-Hahn ${ }^{1}$, T Konen $^{1,2}$, AL Frisk $^{1}$, C Schatz ${ }^{1}$, T Krahn $^{1}$, \\ O von Ahsen ${ }^{?}$ \\ ${ }^{1}$ Biomarker Research, Bayer AG, Berlin and ${ }^{2}$ Department of NanoBiophotonics, Max Planck Institute for Biophysical \\ Chemistry, Göttingen, Germany
}

Accepted June 05, 2017

\begin{abstract}
Determination of predictive biomarkers by immunohistochemistry (IHC) relies on antibodies with high selectivity. RNA in situ hybridization (RNA ISH) may be used to confirm IHC and may potentially replace it if suitable antibodies are not available or are insufficiently selective to discriminate closely related protein isoforms. We validated RNA ISH as specificity control for IHC and as a potential alternative method for selecting patients for treatment with MET inhibitors MET, the HGF receptor, is encoded by the MET proto-oncogene that may be activated by mutation or amplification. MET expression and activity were tested in a panel of control cell lines. MET could be detected in formalin fixed paraffin, embedded (FFPE) samples by IHC and RNA ISH, and this was confirmed by sandwich immunoassays of fresh frozen samples. Gastric cancer cell lines with high MET expression and phosphorylation of tyrosine-1349 respond to the MET inhibitor, BAY-853474. High expression and phosphorylation of MET is a predictive biomarker for response to MET inhibitors. We then analyzed MET expression and activity in a matched set of FFPE vs, fresh frozen tum or samples consisting of 20 cases of gastric cancer. Two of 20 clinical samples investigated exhibited high MET expression with RNA ISH and IHC. Both cases were shown by sandwich immunoassays to exhibits strong functional activity. Expression levels and functional activity in these two cases were in a range that predicted response to treatment. Our findings indicate that owing to its high selectivity, RNA ISH can be used to confirm findings obtained by IHC and potentially may replace $\mathrm{IHC}$ for certain targets if no suitable antibodies are available. RNA ISH is a valid platform for testing predictive biomarkers for patient selection.
\end{abstract}

Key words: im munohistochemistry, MET, RNA ISH, sandwich immunoassay

The development of new cancer therapies increasingly depends on the use of predictive biomarkers for patient selection, because targeted therapies

Correspondence: Oliver von Ahsen, Biomarker Research, Bayer AG, Mullerstrasse 178, 13353 Berlin, Germany. Phone: $+49-30-468192280$, fax: $+49-30-468992280$, e-mail: oliver vonahsen@bayer com

Color versions of one or more of the figures in the article can be found online at www tandfonline.com/ibih

C. 2017 The Biological Stain Commission

Biotechnic \& Histochemistry 2017, Early Online: 1-11 address decreasing subpopulations. Because biomarkers are becoming increasingly embedded into the early phases of drug development, understanding the target biology, and robust and validated assays are essential for identifying the appropriate patients for particular treatments.

The use of predictive biomarkers for patient selection faces three major challenges: availability of relevant tumor material, in tratum or heterogeneity and availability of validated assays. Also important, however, is the development of a 
responder hypothesis, which defines a quantitative threshold that is necessary for response to treatment during preclinical studies. From a series of preclinical models, the properties necessary for response to treatment, e.g, the extent of target expression, must be deduced. The biomarker assay must be sensitive and robust, especially near the response threshold, to discriminate potential responders from non-responders.

Gastric cancer is the third most frequent cause of death from cancer among men and fifth among women worldwide. More than 700,000 deaths worldwide and 10,700 deaths in the US are caused by gastric cancer each year (Torre et al. 2015, Siegel et a1. 2016). Although the prognosis is very good for cases of asymptomatic early stage disease detected by endoscopic screening (Ono et al. 2001, Yada et al. 2013), the prognosis is poor for advanced cancer stages with less than one year median survival with conventional chemotherapies (Bilici 2014).

Trastuzumab was approved in 2010 as the first targeted agent for advanced gastric cancer. Her2 amplifications or overexpression have been reported in 7-34\% of investigated tumors (Gravalos and Jimeno 2008) and trastuzumab combined with chemotherapy improved overall survival significantly compared to chemotherapy alone (Bang et al, 2010). Consequently, trastuzumab has been approved for treatment of $\mathrm{Her} 2$ positive advanced gastric cancer.

The vascular end othelial growth factor (VEGF) receptor antibody, ramucirumab, was the second targeted agent approved for treatment of gastric cancer, although not in a selected patient population (Wilke et al 2014).

The receptor tyrosine kinase, MET, was discovered in 1984 as part of an oncogenic fusion protein, TPR-MET, in a carcinogen-treated cell line. The name MET was chosen after the carcinogen ( $n$ methyl-N -nitro-N-nitrosoguanidine) used in the study that caused the appearance of the TPR-MET fusion protein (Cooper et al. 1984). Its causative role in cancer development was confirmed by the discovery of activating mutations in its kinase domain causing constitutive kinase activity in hereditary renal papillary carcinomas (Schmidt et al. 1997). The role of MET in development, tissue regeneration and cancer has been reviewed extensively (Trusolino et al. 2010, Gherardi et al. 2012, Peters and Adjei 2012, Ghiso and Giord ano 2013). MET overexpression has been reported in many cancer types and this is associated with poor prognosis. Strong overexpression caused by genomic amplification of the MET gene has been described in gastric cancer (Giord ano et al. 1989, Kiyose et al. 2012) and in response to treatment with epidermal growth factor receptor (EGFR) targeting drugs such as gefitinib for non-small cell lung cancer (Engelman et al. 2007) and with cetuximab for colorectal cancer (Bardelli et al. 2013). These findings led to the development of $23 \mathrm{small}$ molecule inhibitors and antibodies that target MET and its ligand, hepatocyte growth factor (HGF); more than 240 clinical trials were conducted in 2014 (Furlan et al. 2014). The first phase three trial on a tyrosine kinase inhibitor, tivantinib, or non-small cell lung carcinoma (NSCLC), however, was terminated owing to lack of efficacy. Further studies currently are underway using a population with high MET expression. Also, the development of the singlearmed MET antibody, onartuzumab, was stopped at phase three, although phase two had produced promising results (Spigel et al. 20/3). Both studies failed to reach the primary end point of improved overall survival, although the drugs exhibited significant efficacy in preclinical studies.

The history described above emphasizes the need for an appropriate patient selection strategy (Garber 2014, Hirsch et al. 2014). In our experience, many anti-MET antibodies are only weakly selective. Typical immunohistochemistry (IHC) assays demonstrate MET over-expression in $\leq 50 \%$ of NSCLC cases depending on the antibodies used; however, in only $5 \%$ of cases the pathway is actively generating signals, as shown by receptor phosphorylation (Tsuta et al. 20/2). The findings described above suggest that the commonly used IHC approach has selectivity problems. This was corroborated by a recent report that $>50 \%$ of the MET positive cases by $\mathrm{IHC}$ could not be confirmed by mass spectrometry. A perfect match, however, was reported between genomic amplification and mass spectrometry (Catenacci et al. 2014).

Clinical findings also support the use of FISH analysis of gene amplification as a predictive biomarker. Crizotinib achieved an objective response in two thirds of FISH positive cases (Sholl et al. 2013). This finding supports the use of FISH analysis for patient selection; however, this method is expensive and laborious compared to IHC, and it is not available in every clinical laboratory. Moreover, gene amplifications can be non-functional, as described for $5-10 \%$ of the Her 2 FISH positive breast cancer cases without Her 2 mRNA or protein expression (Luoh et al 2013). For fibroblast growth factor receptor $1, \mathrm{mRNA}$ and protein expression, but not gene copy numbers, were found to predict sensitivity toward FGFR inhibitors (Wynes et al. 2014). 
RNA ISH is closer to the most relevant biomarker, which would be protein expression if not functional activity. By contrast to detection of proteins by IHC, detection of the coding mRNA is independent of antibodies and is highly sensitive and selective according to the design of the oligo-probes (Wang et al. 2012). This technique recently has been used to detect MET RNA in FFPE tissue samples and produced a good correlation with both IHC and clinical relevance by correlation with prognosis (Choi et al. 2014).

In addition to highly specific and validated assays, a clear and quantitative responder hypothesis is required to develop a targeted therapy. To obtain statistically significant findings, only patients who have the potential to respond to treatment should be recruited for the study. Traditionally, the expression of a target, which was selected based on reports of its overexpression compared to normal tissue was sufficient for participation in a clinical study. We propose, however, that a quantitative responder hypothesis should be generated and that patients be recruited accordingly

Because successful clinical development of targeted therapies depends on carefully selected patients, we set out to confirm the feasibility of RNA ISH for detection of functionally relevant expression levels of MET that are predictive of oncogenic addiction. Two among 20 cases of gastric cancer with high expression and activity levels in sandwich immunoassays, by IHC and confirmed by mass spectrometry were clearly identified by RNA ISH. Therefore, we consider that RNA ISH is a valuable additional control for IHC, and potentially an alternative method for patient selection.

\section{Materials and methods}

Anonymized tumor samples were purchased from Indivumed ( $w w w$ indivumed com) (Hamburg, Germany). Sample collection was performed according to the principles of good clinical practice stated in the Declaration of Helsinki (1964). We used double-blinded historical samples from donors who had given informed consent for research on the samples for commercial purposes. The need for ethics committee approval was waived by the local institutional review board (Hamburger Ärztekammer), because samples were obtained from patients undergoing surgical removal of their primary tumors with curative intent and no additional procedures were necessary. All samples were obtained from the resected tumor material post-surgery. Small blood samples were obtained from the venous access required for the surgery. Informed consent was obtained and use of the samples after double-blinding was approved by the local data protection officer, the "Hamburgische Beauftragte fuer Datenschutz und Informationssicherheit" in Hamburg, Germany

We used 20 cases of gastric cancers at different stages that were removed during surgery. We obtained matched samples from the same excised tumor, either fresh frozen or FFPE. All cell lines were obtained from ATCC (Manassas, VA) and grown in RPMI1640 (F1215; Biochrom, Berlin, Germany), Iscove Basal Medium (F0465; Biochrom) or DMEM (4166-029; ThermoFisher Scientific, Waltham, MA), supplemented with $10 \%$ fetal calf serum and $2 \mathrm{mM}$ glutamine.

BAY 853474 is a reversible, ATP-competitive inhibitor of MET. It inhibits MET with an IC 50 of $1 \mathrm{nM}$ in the biochemical assay and $2.9 \mathrm{nM}$ in a cell based mechanistic assay. BAY 853474 is highly selective; it inhibits only Rsk2 with IC 50 of 906 $\mathrm{nM}$ and causes $<50 \%$ inhibition of Rsk 1 , Rsk3, Flt 1 , MKK6, PKG $\alpha$ and PKG $\beta$ at $1 \mu \mathrm{M}$.

To generate cell lysates, cells were grown to $70 \%$ confluence in a $\mathrm{T} 75$ flask, washed with phosphate buffered saline (PBS) and frozen in liquid nitrogen for later preparation of lysates using $500-900 \mu \mathrm{l}$ MSD lysis buffer supplemented with phosphatase inhibitor cocktail (P0044 and P-5726, respectively (Sigma, Munich, Germany) and Halt protease inhibitor cocktail (87785; Pierce/ ThermoFisher Scientific). Cell lysates were aliquoted, then stored at $-80^{\circ} \mathrm{C}$ before use for sandwich immunoassays or western blotting.

Cell pellets were prepared from washed cells in an Eppendorf tube by $10 \mathrm{~min}$ centrifugation at $2,000 \times \mathrm{g}$ followed by fixation in $10 \%$ neutral buffered formalin for 8-18 h at room temperature. The pellets were stored in $70 \%$ ethanol until embedment in paraffin using a vacuum infiltrator (ASP200S; Leica, Nussloch, Germany).

RNA ISH analysis of MET expression was performed using RNAscope 2.0 reagents from Advanced Cell Diagnostics, (ACD; Hayward, CA) according to the manufacturer's instructions. mRNA specific probes specific for MET and ubiquitin were designed by ACD. Pretreatment protocol 2 was used for $15 \mathrm{~min}$. For better discrimination of moderate and strong expression, we adjusted the scoring according to the following system: 0 , no staining or $<1 \mathrm{dot} /$ cell; 1, 1-3 dots/ cell; 2, 4-10 dots/ cell with no or few dot clusters; score $3,>10$ dots/ cell with fewer than $10 \%$ positive cells with dot clusters; $4,>10$ dots/ cell and $>10 \%$ positive 
cells with dot clusters; $5, \geq 10$ dots/ cell with $>50 \%$ positive cells with dot clusters.

The antibody clone, SP44 (Spring Biosciences, Pleasanton, CA), diluted $1: 100$ in antibody diluent (S2022; Dako, Glostrup, Denmark) was used for IHC. Antigen retrieval was performed in $\mathrm{pH} 9$ target retrieval solution (S2367; Dako) for $17 \mathrm{~min}$ in a pressure cooker. Staining was performed using the Dako Envision system. Evaluation and scoring of ISH and IHC were performed by a board-certified pathologist (AF).

MET expression and phosphorylation of tyrosine-1349 were analyzed by electrochemiluminescence-based sandwich immunoassays (Mesoscale Discovery, Rockville, MD) in lysates made from fresh frozen tumor material or exponentially growing cell cultures. Cells were harvested by trypsinization, washed twice with PBS and lysed in MSD lysis buffer supplemented with Halt protease inhibitor cocktail (87785; Pierce/ ThermoFisher Scientific) and phosphatase inhibitors (P0044 and P-5726, respectively; Sigma). Protein concentration in the lysates was determined using the Bradford assay (Bradford 1976). A protein content of $20 \mu \mathrm{g} /$ well was used and the results are reported as MSD counts/ $\mu \mathrm{g}$.

MET expression levels in different cell lines also were analyzed by western blot. A $10 \mu \mathrm{g}$ protein extract of exponentially growing cells was loaded on a NuPAGE Novex 4-12\% Bis-Tris Mini Gel, blotted on to a nitrocellulose membrane and detected using IRDye conjugated secondary antibodies. The monoclonal antibody, SP44 (Spring Biosciences), diluted $1: 500$ in tris-buffered saline containing Tween 20 (TBST) was used as primary antibody

For proliferation assays, cells were seeded at 2,000 cells/well in 96 well plates, grown for $24 \mathrm{~h}$, then BAY 853474 was added. Cell culture was continued for $72 \mathrm{~h}$, then viability was determined using the CellTiter-Glo Luminescent Cell Viability Assay (Promega, Mannheim, Germany). For selected reaction monitoring (SRM) analysis, 10 $\mu \mathrm{m}$ tissue sections were cut using a Thermo S2055 microtome (Thermo Fisher Scientific, San Jose, CA), then microdissected to maximize tumor content. Samples were processed for SRM analysis using a TSQ Vantage triple quadrupole mass spectrometer as described earlier (Catenacci et al. 2014).

\section{Results}

To test the performance of the different assay techniques and to define a relevant level of MET activity for gastric cancer, we uséd a panel of different gastric cancer cell lines. Three of the cell lines (MKN45, HS746T, SNU-5), which are known to exhibit a genomic MET gene amplification, were u sed as positive controls. The MET gene amplification causes MET overexpression, its ligand-independent autophosphorylation and activation of downstream intracellular signaling pathways (MKN45, HS746T and SNU-5 cells) have 12, 22 and 20 gene copies, respectively (Wang et al. 2010). For comparison, we used three other gastric cancer cell lines without MET amplification. The lung cancer cell lines, H520 and H661, served as MET negative controls as described by Tang et al. (2008). The gold standard for specificity is the use of sandwich immunoassays using two antibodies

We first tested the expression and phosphorylation of MET in lysates prepared from exponentially growing cells using commercially available sandwich immunoassays. Figure la shows the expression levels of MET and Fig Ib shows the phosphorylation of tyrosine-1349, which is
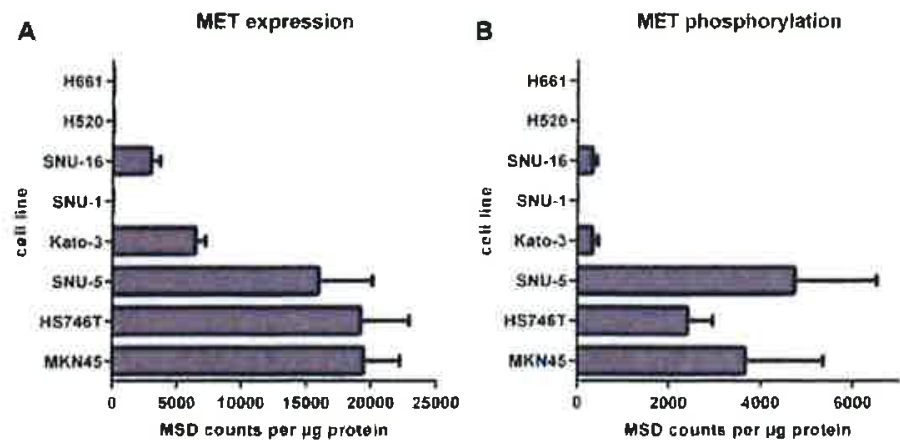

Fig. 1. Expression and autophosphorylation levels of MET in various cell lines. A) Expression of MET in different cell lines tested by a sandwich immunoassay (MSD). B) Phosphorylation of tyrosine-1349 in different cell lines as shown by MSD.

4 Biotechnic \& Histochemistry 2017, Early Online: 1-11 
phosphorylated after receptor dimerization and serves as a docking site for the intracellular adaptor protein, Gabl (Lock et al 2003). The cell lines with MET amplification show very strong expression; two other gastric cancer cell lines, Kato-3 and SNU-16, exhibit moderate MET expression, while SNU-1 cells are MET-negative (Wang et al, 2016). The MET negative lung cancer cell lines, H520 and H661, also confirmed the specificity of the assay. The MET expression levels were confirmed by the functional activity as shown by MET autophosphorylation (Fig 16). The SP44 antibody used for IHC here and elsewhere was first tested by western blotting and the MET expression levels were confirmed (data not shown).

We established a staining protocol using the SP44 monoclonal antibody and tested its performance first on formalin fixed cell pellets of the control cell lines. The staining was highly selective and the relative intensities matched the results of the western blot and the sandwich immunoassays (Fig 2a). The performance of the RNA ISH assay on the same cell pellets (Fig. 2b) matched the IHC data.

To define therapeutically relevant expression levels, we compared the response of the cell lines to the MET inhibitor, BAY-853474 (Fig 3a), a highly selective ATP-competitive inhibitor with 1 $\mathrm{nM}$ affinity in biochemical assays. In a three day proliferation assay, BAY-853474 efficiently blocked the growth of MKN45, HS746T and SNU-5 cell lines with double-digit nM potency and $100 \%$ efficacy, which verified the oncogenic addiction of these cell lines to MET (Table 1). Three other gastric cancer cell lines and the MET negative control cell lines failed to exhibit a response to MET inhibition. These results are consistent with the report by Wang et al. (2016), who found that HS746T, SNU-5 and MKN45 were responsive to both ABT700 , an anti-MET antibody and the MET-kinase inhibitor, PF-4217903, whereas SNU-16, Kato-3<smiles>CC1=C(C#N)C(c2ccc3[nH]nc(C)c3c2)C(C#N)=C(C)N1</smiles>

Fig. 3. BAY-853474, a potent selective MET inhibitor.

and SNU-I did not respond to these compounds The same findings also had been reported earlier for the MET inhibitor PHA-665752 (Smolen et al. 2006), which demonstrated the same result independent of the inhibitors used. These cells grow without requiring MET signaling; the MET inhibitor, BAY-853474, has no measurable effect on these cells. This was surprising because Kato-3 and SNU16 cells express MET and exhibit active phosphorylation of tyrosine-1349. This finding suggests that careful determination of a response threshold is required for clinical studies. The preclinical values obtained here generate a first responder hypothesis. An IHC score $>2$ is required; a score of 3 appears to be sufficient. An RNA ISH score $>2$ is required, a RNA ISH score of 4 appears to be sufficient. More than 6,000 counts/ $\mu \mathrm{g}$ MET and 500 counts/ $\mu \mathrm{g}$ phosphotyrosine-1349 would be necessary for a response to treatment. After creating the IHC and RNA ISH assays, we used a set of 20 clinical cases of gastric cancer to test the performance of the assays on clinical FFPE samples. In IHC, two of 20 gastric cancer samples stained strongly for MET, while two other cases showed areas of moderate intensity. Most of the samples stained weakly or did not stain. Figure 4 shows
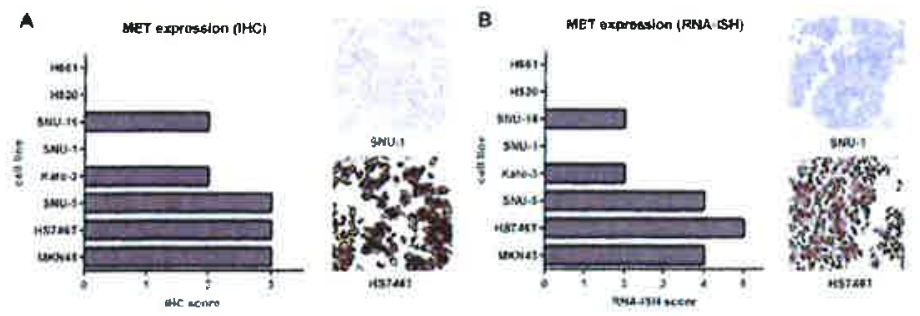

Fig. 2. Expression of MET in various cell lines assessed by IHC vs. RNA in situ hybridization. A) Expression of MET in different cell lines tested by $\mathrm{IHC}$, with examples for negative and score of 3 staining. B) Expression of MET in different cell lines tested by RNA ISH, with examples for negative and score of 5 staining. Scale bars $=50 \mu \mathrm{m}$. 
Table 1. IC50 and efficacy of BAY-853474 in $72 \mathrm{~h}$ proliferation assay on different gastric and lung cancer cell lines, and correlated with MET expression levels

\begin{tabular}{|c|c|c|c|c|c|c|c|c|}
\hline Cell line & MKN45 & $\mathrm{HS} 746 \mathrm{~T}$ & SNU-5 & Kato-3 & SNU-1 & SNU-16 & $\mathrm{H} 520$ & $\mathrm{H} 661$ \\
\hline MET expression (IHC) & +++ & +++ & +++ & ++ & & ++ & & \\
\hline Bay 853474 IC50 & $44 \mathrm{nM}$ & $17 \mathrm{nM}$ & $17 \mathrm{nM}$ & & & & & \\
\hline Bay 853474 efficacy & $98 \%$ & $96 \%$ & $100 \%$ & & & & & \\
\hline
\end{tabular}

representative images of the outcomes including all moderately and strongly stained samples.

High expression of MET was confirmed by strong signals for MET RNA using in situ hybridization (Fig 5). The two cases (A1362 and A1516) that displayed strong signals with IHC were confirmed by high RNA levels. These findings are consistent with the literature concerning the prevalence of MET amplification in gastric cancer. A recent review identified $8-21 \%$ amplifications (Peng et al. 2014). The prevalence of MET amplification may be lower in Japanese patients (Kiyose et al. 20I2). Two more cases (A1525 and A1550) showed moderate IHC signals. These moderate expressers could not be confirmed by elevated RNA signals, because the RNA signals for these samples were within the commonly observed weak signal intensity range. The comparison between IHC and ISH results is summarized in Fig 5a,b.

Because a potential drawback of RNA ISH is its sensitivity to RNA degradation, we controlled the RNA levels by testing for the presence of ubiquitin RNA. Fig. 6 shows high levels of ubiquitin C RNA in sample A1525, whereas. MET RNA levels are very low. We can rule out issues of RNA quality as the reason for low MET RNA ISH in this case On the other hand, sample A1550 exhibited relatively low levels of ubiquitin RNA, so in this case RNA degradation cannot be ruled out

To extend our understanding of quantitative expression levels, we analyzed matching fresh frozen material from the same tumors using sandwich immunoassay (MSD). Figule 7 shows that the two cases with very high MET expression detected by IHC (Fig 7a) and RNA ISH (Fig 7b) were confirmed by sandwich immunoassay (Fig. 7c). Both

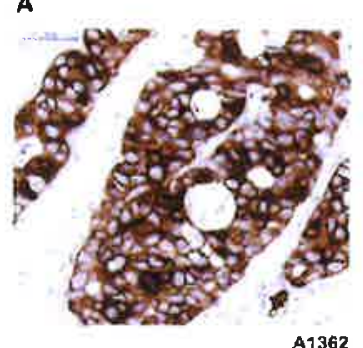

$D$

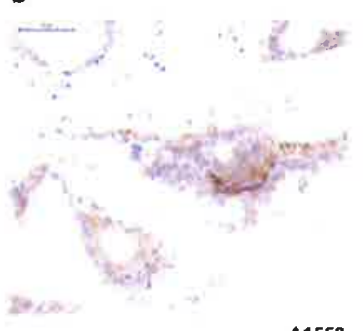

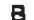

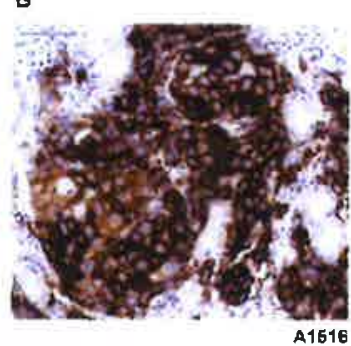

E

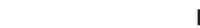

C

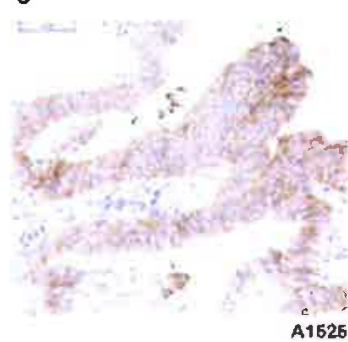

$\mathbf{F}$

A1525

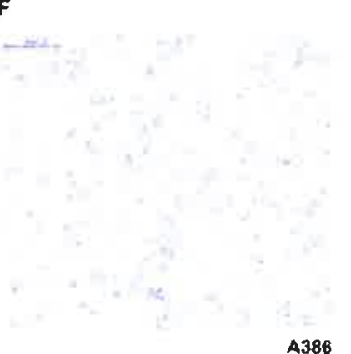

Fig. 4. Examples of different MET expression levels shown by IHC on FFPE gastric cancer samples. A) Sample A1362, IHC score of 3. B) Sample A1516, IHC score of 3. C) Sample A1525, IHC score of 2. D) Sample A1550, IHC score of 2. E) Sample A1602, IHC score of 1. F) Sample A386, IHC score of 0 . Scale bars $=50 \mu \mathrm{m}$.

6 Biotechnic \& Histochemistry 2017, Early Online: 1-11 


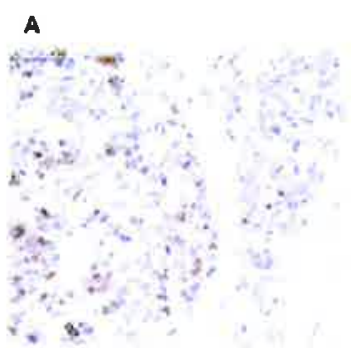

B

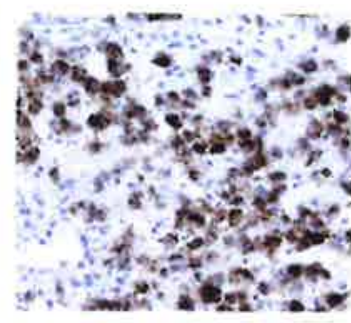

A1362

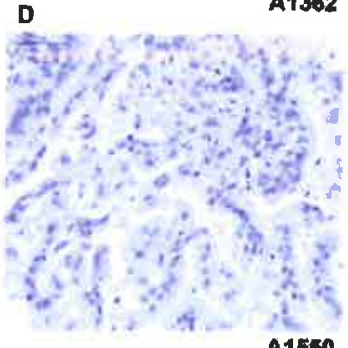

E

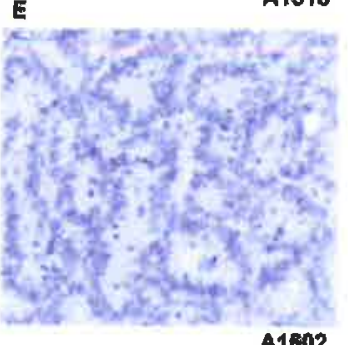

c
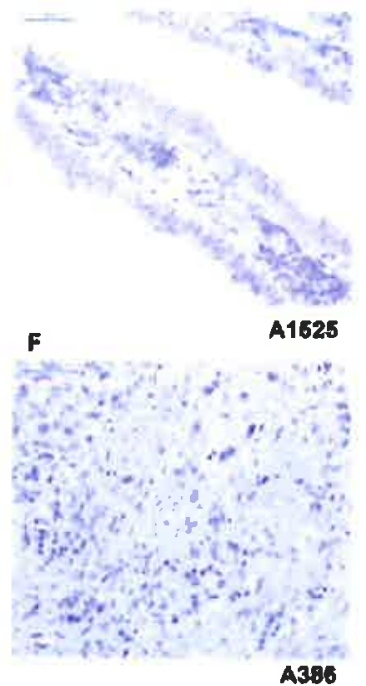

Fig. 5. Examples for different MET RNA levels shown by RNA ISH on FFPE gastric cancer samples. A) Sample A1362, RNA ISH score of 3. B) Sample A1516, RNA ISH score of 4. C) Sample A1525, RNA ISH score of 1. D) Sample A1550, RNA ISH score of 1. E) Sample A1602, RNA ISH score of 1. F) Sample A386, RNA ISH score of 0. Scale bars $=50 \mu \mathrm{m}$.

A

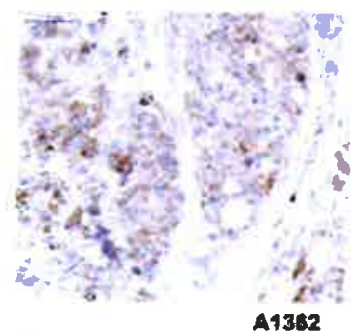

C

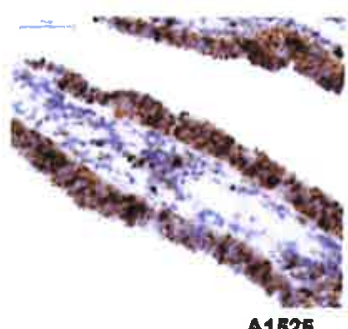

B

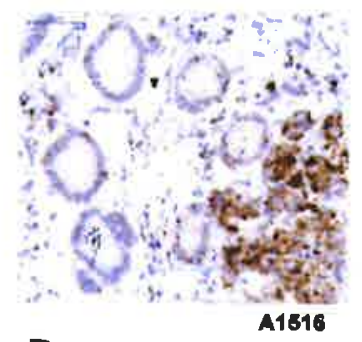

D

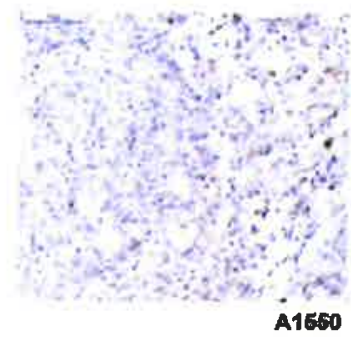

Fig. 6. Control for integrity of the RNA in FFPE cell pellets by in situ hybridization of ubiquitin as housekeeping gene control. A) Sample A1362, RNA ISH score of 4. B) Sample A1516, RNA ISH score of 4. C) Sample A1525, RNA ISH score of 5. D) Sample A1550, RNA ISH score of 2. Scale bar $=50 \mu \mathrm{m}$.

cases also exhibit active signaling as demonstrated by high phosphorylation of tyrosine-1349 (Fig. 7d). The phosphorylation levels are within the range for cell lines with oncogenic addiction to MET activity as shown in Fig. 1. This result show s that functionally relevant MET expression levels can be detected by RNA ISH and confirmed by ELISA-like approaches. Only one of the two moderate

MET expression analysis by RNA in situ hybridization 7 
MET axpression (IMC)

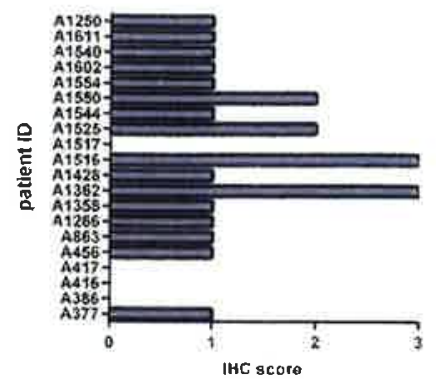

C

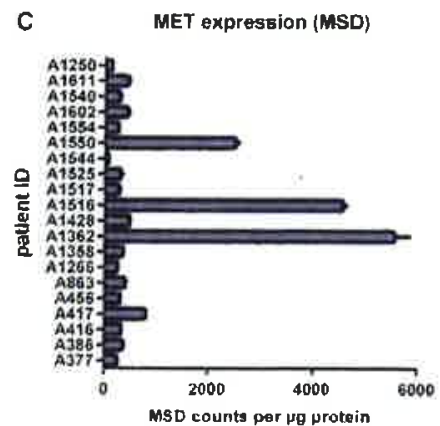

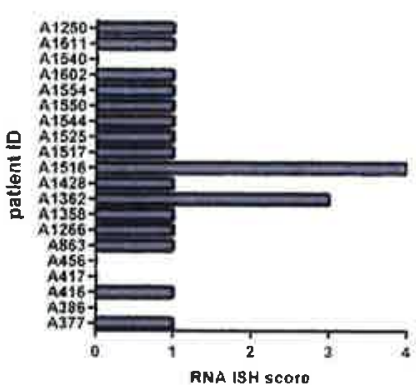

D

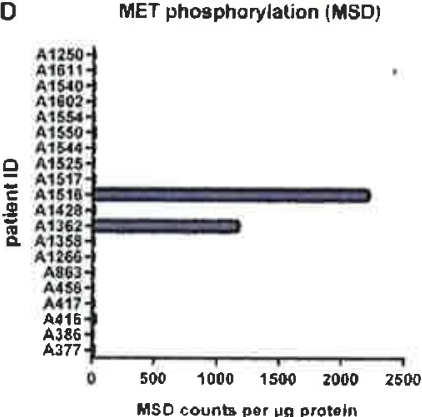

Fig. 7. MET expression tested by IHC compared to the presence of MET RNA detected by RNA ISH (A) and FFPE samples (B). The results were confirmed by testing matched fresh frozen samples for MET expression (C) and phosphorylation of tyrosine-1349 (D) as indicators of molecular activation by Mesoscale Discovery (MSD) assays.

expressers (A1550) could be confirmed by sandwich immunoassay, but it did not exhibit increased phosphorylation. Case A 1525 could not be confirmed in any way. A possible explanation for this may be local heterogeneity in the tumor as even the matched samples were derived from different parts of the tumor. Potentially, the matched fresh frozen sample contained a very limited number of tumor cells. An alternative explanation would be false positive staining by IHC, although the clear membrane staining restricted to the epithelial layer appeared to be specific. As another independent control, we analyzed FFPE material by mass spectrometry The two high expressers were confirmed (A1362 with $3,23 \mathrm{fmol} / \mu \mathrm{g}$ and A 1516 with $4.60 \mathrm{fmol} / \mu \mathrm{g}$ ) using this method, but the questionable cases with moderate IHC staining were below the detection limit of mass spectrometry as were all other cases except A 1250 with 0.39 $\mathrm{fmol} / \mu \mathrm{g}$ )

Taken together, our findings demonstrate that RNA in situ hybridization on FFPE material is feasible and sufficiently sensitive to detect high levels of MET expression with high specificity.
Using the FFPE material for IHC and RNA ISH is a good complement to stringent specificity control.

\section{Discussion}

Immunohistochemistry on FFPE tissue currently is the standard method for patient selection based on target expression. The small dynamic range and the high potential for cross reactivity, however, are major issues with this method. The recent failure of Genentech's phase 3 study of onartuzumab raised concerns about a patient selection strategy based on MET IHC (Garber 2014, Hirsch et al. 2014).

We experienced false positive staining on tumor samples using several other commercially available MET antibodies (data not shown). We made similar experiences for phospho-site specific antibodies. An antibody directed against the activation loop phospho-sites exhibited strong cross reaction with activated EGFR, and also an antibody against the intracellular docking site, phosphotyrosine-1349, stained nearly all tested clinical samples despite appearing to be specific for a small 
panel of cell line controls. The limitations of IHC for patient selection for anti-MET therapy have been summarized by Lee et al. (2016). These investigators reported that MET positivity could not be confirmed by DNA-FISH in many studies. These reports are consistent with that of Watermann et al. (2015), who described lack of correlation between MET gene amplification, protein expression and phosphorylation using the same antibodies on NSCLC samples. Kawakami and Okamoto (2016) proposed to recruit patients based only on DNAFISH positivity. This would ensure high specificity, but unfortunately, DNA-FISH is compromised by in ter-operator variability, false negative results and the potential lack of expression of amplified sequences.

We established a new MET IHC method using the SP44 antibody plus an RNA ISH assay as an antibody-independent specificity control suitable for use with FFPE $m$ aterial. Using high quality samples, we have shown here that RNA ISH is a valuable tool for confirming target expression in tumor samples, at least for high expression levels. Our approach appears valid for oncogenic drivers, such as Her2 and MET, that are highly overexpressed owing to genomic amplification of their coding sequences.

The suitability of RNA ISH for detecting HER2 mRNA in breast cancer has been demonstrated and RNA ISH sensitivity has been shown to be higher compared to DNA FISH for gene amplification (Bernet et al. 2012). This suggests that an additional $7 \%$ of breast cancer patients may be eligible for herceptin therapy (Bernet et al. 2012). Her2 detection by RNA ISH correlates well with IHC and DNA-FISH (Vassilakopoulou et al. 2014). HER2 expression also could be detected reliably by RNA ISH in gastric cancer (Kim et al. 2013). We confirm here the applicability of RNA ISH for analyzing MET expression in FFPE samples. We have shown for MET that alternative methods, such as RNA ISH, can be used to identify biologically relevant overexpression levels associated with response to treatment at least in cell culture.

We believe that generating a quantitative responder hypothesis before establishing thresholds in a clinical study is critical for successful clinical studies. Often, the fact that expression of a protein is associated with bad prognosis is used as evidence for its functional importance, but we propose that experimental proof of its functional importance as a tumor driver is necessary. Of course, a preclinical responder hypothesis can only indicate which level of biomarker expression is required; the actual threshold for response can be determined only in a well-designed clinical trial with retrospective biomarker analysis

Because active molecular signaling is driving the cancer, it is advisable to analyze the MET phosphorylation levels rather than MET protein expression alone. The sandwich immunoassay for MET phosphorylation was the most selective and relevant assay among the assays characterized here; it was quantitative and produced the best signal to background level of the assays tested. In principle, the sandwich immunoassay is the best assay for selecting patients for MET inhibitor therapy. Because fresh biopsies are not common for screening purposes, however, analyses still must be based on historical FFPE material for the foreseeable future.

A combination of IHC and RNA ISH for specificity control is a practical approach, because the results correlate with MET phosphorylation. Tumor heterogeneity is a potential issue for biopsy based treatment decisions. The fact that the investigator can judge the heterogeneity of the sample and evaluate the tumor cells remains an advantage of histology based methods. In this respect, the possibility of controlling the selectivity of IHC by using RNA ISH constitutes a big step forward. Of course, preservation of RNA by rapid fixation and good sample handling is a prerequisite. Larger studies are required to determine whether the RNA ISH method is sufficiently robust for routine use in clinical settings In addition, RNA integrity must be controlled by testing the expression of hou sekeeping genes such as ubiquitin or cyclophilin

We demonstrated the feasibility of RNA ISH for detecting functionally relevant expression levels of MET in FFPE gastric cancer samples. Our findings demonstrate the potential of the RNA ISH method as a validation tool to verify the specificity of new antibodies. This highly selective method also may be useful for studies for which no suitable antibodies are available or when several homologous protein isoforms must be discrim inated.

\section{Acknowledgments}

We thank Sami Khaznadar for the critical reading of the manuscript. This work was funded solely by the Bayer AG.

Declaration of interest: The authors report no conflicts of interest. The authors alone are responsible for the content and writing of this paper. 


\section{References}

Bang Y $Y$ Van Cutsem E, Feyereislova A, Chung HC, Shen L, Sawaki A, Lordick F, Ohtsu A, Omuro Y, Satoh T, Aprile G, Kulikov E, Hill J, Lehle M, Ruschoff d Kang YK (2010) Trastuzumab in combination with chemotherapy versus chemotherapy alone for treatment of HER2-positive advanced gastric or gastro-oesophageal junction cancer (ToGA): a phase 3, open-label, rando$m$ ised controlled trial. Lanot 376: 687-697.

Bardeli A, Corso S, Bertotti A, Hobor S, Valtorta E Siravegna G, Sartore-Bianchi A, Scala E, Cassingena A, Zecchin D, A picala M, Migliardi G, Galimi F, Lauricella C, Zanon C, Perera T, Veronese S, Corti G, Amatu A, Gambacorta M, Diaz LAJt, Sausen M, Velaulescu VE Comoglio P, Trusolino L, Di Nicolantonio F, GiordanoS, Siena S (2013) Amplification of the MET receptor drives resistance to anti-EGFR therapies in colorectal cancer. Cancr Disoov. 3: 658-673

Bernet $L$, Martinez Benaclocha $M$, Castera $C$, Cano Munoz R, Sevilla F, Alba d de Dios Barranco $t$, Cordoba A, Garcia-Caballero T, Hardisson D, de Francisco Hernandez MM, Lazaro MM, Polo L, Riu F, Rezola R, Rojo F, Ruiz I, Hernandiz A, de la Camara de Las Heras $\mathbb{M}$, Coupe VM (2012) mRNA in situ hybridization (HistoSonda): a new diagnostic tool for HER2-status in breast cancer-a multicentric Spanish study. Diagn. Md. Pathd. Pat B. 21:84-92.

Bilici A (2014) Treatment options in patients with metastatic gastric cancer: current status and future perspectives. World $\downarrow$ Gastroented 20: 3905-3915.

Bradford MM (1976) Rapid and sensitive method for the quantitation of microgram quantities of protein utilizing the principle of protein-dye bind ing. Anal. Biochem. 72: 248-254. Catenacci DV, Liao WL, Thyparambil S, Henderson L, Xu P, Zhao L, Rambo B, Hart J, Xizo SY, Bengali K, Uzzell J, Darfler M, Krizman DB, Cecchi F, Bottaro DP, Karrison T, Veenstra TD, Hembrough T, Burrows $J$ (2014) Absolute quantitation of Met using mass spectrometry for clinical application: assay precision, stability, and correlation with MET gene amplification in FFPE tumor tissue. Plos ONE 9 (7): el 100586.

Choi J, Lee HE, Kim MA, Jang BG, Lee HS, Kim WH (2014) Analysis of MET mRNA expression in gastric cancers using RNA in situ hybridization assay: its clinical implication and comparison with immunohistochemistry and silver in situ hybridization. PIOS ONE 9 (11): e 111658.

Cooper CS, Park M, Blair DG, Tainsky M A, Huebner K, Croce CM, Vande Woude GF (1984) Molecular cloning of a new transforming gene from a chemically transformed human cell line. Nature 311: 29-33.

Engelman $J A$, Zejnullahu $K$, Mitsudomi $T$, Song $Y$, Hyland C, Park JO, Lindeman N, Gale CM, Zhao X Christensen J, Kosaka T, Holmes Ad, Rogers AM, Cappuzzo F, M ok T, Lee C, Johnson BE Cantley LC, Janne PA (2007) MET amplification leads to gefitinib resistance in lung cancer by activating ERBB3 signaling. Soience 316: 1039-1043.
Furlan $A$, Kherrouche $Z$, Montagne R, Copin MC Tulasne D (2014) Thirty years of research on met receptor to move a biomarker from bench to bed side. Canor Res. 74: 6737-6744.

Garber K (2014) MET inhibitors start on road to recovery. Nat. Rev. Drug Discov. 13: 563-565.

Gherardi E Birchmeier W, Birchmeier C, Vande Woude $G$ (2012) Targeting MET in cancer: rationale and progress. Nat. Rer. Cancer 12: 89-103.

Ghiso E Giordano S (2013) Targeting MET: why, where and how? Curr. Opin. Pharmacol. 13: 511-518.

Giordano S, Ponzetto C, Di Renzo MF, Cooper CS, Comoglio PM (1989) Tyrosine kinase receptor indistinguishable from the c-met protein. Nature 339: 155-156. Gravalos C, Jimeno A (2008) HER2 in gastric cancer: a new prognostic factor and a novel therapeutic target. Ann. Oncol. 19: 1523-1529.

Hirsch FR, Bunn PA $\downarrow$, Herbst RS (2014) "Companion diagnostics": has their time come and gone? Clin. Canc Res 20: 4422-4424

Kawakami H, Okamoto I (2016) MET-targeted therapy for gastric cancer: the importance of a biomarker-based strategy. Gastric Canor 19: 687-695.

Kim MA, Jung JE, Le HE, Yang HK, Kim WH (2013) In situ analysis of HER2 $m$ RNA in gastric carcinoma: com parison with fluorescence in situ hybridization, dualcolor silver in situ hybridization, and immunohistochem istry. Hum. Pathol. 44: 487-494.

Kiyose S, Nagura K, Tao H, Igarashi $H$, Yamada $H$, Goto $M, M$ aeda $M$, Kurabe N, Suzuki $M$, Tsuboi $M$ Kahyo T, Shinmura K, Hattori N, Sugimura H (2012) Detection of kinase amplifications in gastric cancer archives using fluorescence in situ hybridization. Pathd. Int. 62: 477-484.

Klotz M, Schmid E Steiner-Hahn K, Rose T, Laube Roese L, Henderson D, Krahn T, von Ahsen O (2012) Preclinical evaluation of biomarkers for response monitoring to the MET inhibitor BA Y-853474. Bionekers 17:325-335. Lee $\downarrow$ Tran P, Klempner SJ (2016) Targeting the MET pathway in gastric and oesophageal cancers: refining the optimal approach. Clin. Oncd. 28: e35-e44.

Lock LS, Frigault MM, Saucier C, Park M (2003) Grb2independent recruitment of Gab1 requires the C-terminal lobe and structural integrity of the Met receptor kinase domain. I Bid. Chem. 278: 30083-30090. Luoh SW, Ramsey B, Hanlon Newell A, Troxell M, Hu Z, Chin K, Spellman P, OIson S, Keenan E (2013) HER2 gene amplification in human breast cancer without concurrent HER-2 over-expression. SpringerPlus 2: 386.

Ono $\mathrm{H}$, Kondo $\mathrm{H}$, Gotoda T, Shirao K, Yamaguchi $\mathrm{H}$ Saito D, Hosokawa K, Shimoda T, Yoshida S (2001) Endoscopic mucosal resection for treatment of early gastric cancer. Gut 48: 225-229.

Peng Z, Zhu Y, Wang Q, Gao d Li Y, Li Y, Ge S, Shen L (2014) Prognostic significance of MET amplification and expression in gastric cancer: a systematic review with meta-analysis. PloS ONE 9 (1): e84502.

Peters S, Adjei AA (2012) MET: a promising anticancer therapeutic target. Nat. Rev. Clin. Onod. 9: 314-326. 
Schmidt L, Duh FM, Chen F, Kishida T, Glenn G, Choyke P, Scherer SW, Zhuang Z, Lubensky I, Dean $M$, Allikmets $R$, Chidambaram A, Bergerheim UR, Feltis $J$, Casadevall C, Zamarron A, Bernues $M$, Richard S, Lips CJ, Walther MM, Tsui LC, Geil L, Orcutt ML, Stackhouse T, Lipan I Slife L, Brauch H, Decker $\perp$ Ni ehans G, Hughson M D, M och H, Storkel S, Lerman MI, Linehan WM, Zbar B (1997) Germline and somatic mutations in the tyrosine kinase domain of the MET proto-oncogene in papillary renal carcinomas. Nat. Gene. 16: 68-73.

Sholl LM, Weremowicz S, Gray SW, Wong KK, Chirieac LR, Lindeman NI, Hornick $\mathrm{L}$ (2013) Combined use of ALK immunohistochemistry and FISH for optimal detection of ALK-rearranged lung adenocarcinomas. I Thor. Onod. 8: 322-328.

Siegel RL, Miller KD, Jemal A (2016) Cancer statistics, 2016. CA Cancer $\downarrow$ Clin. 66: 7-30.

Smolen GA. Sordella R, Muir B, Mohapatra G, Barmettler A, Archibald $\mathrm{H}$, Kim W山, Okimoto RA, Bell DW, Sgroi DC, Christensen JG, Settleman d Haber DA (2006) Amplification of MET may identify a subset of cancers with extreme sensitivity to the selective tyrosine kinase inhibitor PHA-665752. Proc. Nal. Acad. Sd. USA 103: 2316-2321.

Spigel DR, Ervin T」 Ramlau RA, Daniel DB, Goldschmidt $\mathrm{JH} \downarrow$, Blumenschein $G R$ t, Krzakowski M J Robinet G, Godbert B, Barlesi F, Govindan R, Patel T, Orlov SV, Wertheim MS, Yu W, Zha d, Yauch RL, Patel PH, Phan SC, Peterson AC (2013) Randomized phase II trial of onartuzumab in combination with erlotinib in patients with advanced non-small-cell lung cancer. J Clin. Oncod. 31: 4105-4114.

Tang Z, Du R, Jiang S, Wu C, Barkausk as DS, Richey $\downarrow$, Molter J, Lam M, Fask C, Gerson S, Dowlati A, Liu L Lee Z, Hal mos B, Wang Y, Kern $\mathrm{JA}, \mathrm{M}$ a PC (2008) Dual MET-EGFR combinatorial inhibition against T790MEGFR-mediated erlotinib-resistant lung cancer. Brit. J Cancer 99: 911-922.

Torre LA, Bray F, Siegel RL, Ferlay $\downarrow$, Lortet-Tieulent $\downarrow$ Jemal A (2015) Global cancer statistics, 2012. CA Cance $\downarrow$ Clin. 65: 87-108.

Trusolino L, Bertotti A, Comoglio PM (2010) MET signalling: principles and functions in development, organ regeneration and cancer. Na. Rev. Md. Cdl Bid. 11: 834848.

Tsuta K, Kozu Y, Mimae T, Yoshida A, Kohno T, Sekine I, Tamura T, Asamura H, Furuta K, Tsuda $H$
(2012) c-MET/phospho-MET protein expression and MET gene copy number in non-small cell lung carcinomas. $\mathcal{U}$ Thor. Onod. 7: 331-339.

Vassilak opoulou $M$, Togun $T$, Dafni $U$, Cheng $H$, Bordeaux J, Neumeister VM, Bobos $M$ Pentheroudakis G, Skarlos DV, Pectasides D, Kotoula V, Fountzilas G, Rimm DL, Psyrri A (2014) In situ quantitative measurement of HER $2 \mathrm{~m}$ RNA predicts benefit from trastuzumab-containing chemotherapy in a cohort of metastatic breast cancer patients. PIOS ONE 9 e99131.

Wang F, Flanagan $\downarrow$, Su N, Wang LC, Bui S, Nielson A, Wu X, Vo HT, MaXd Luo Y (2012) RNA scope: a novel in situ RNA analysis platform for formalin-fixed, paraffin-embedded tissues. $\perp$ Md. Diagn. 14: 22-29.

Wang J, Goetsch L, Tucker L, Zhang Q, Gonzalez A Vaidya $K S$, Oleksijew $A$, Boghaert $E$ Song $M$. Sokolova I, Pestova $E$ Andérson $M$, Pappano WN Ansell P, Bhathena A, Naumovski L, Corvaia N, Reilly EB (2016) Anti-c-Met monoclonal antibody ABT700 breaks oncogene addiction in tumors with MET amplification. BMC Canor 16: 105.

Watermann I, Schmitt B, Stellmacher F, Muller \& Gaber R, Kugier $C$, Reinmuth N, Huber RM, Thomas $M$, Zabel $P$, Rabe KF, Jonigk D, Warth A, Vollmer $E$ Reck M, Goldmann T (2015) Improved diagnostics targeting c-MET in non-small cell lung cancer: expression, amplification and activation? Diagn. Pathd 10: 130.

Wilke $H$, Muro K, Van Cutsem E On SC, Bodoky G Shimada $Y$, Hironaka $S$, Sugimoto $N$, Lipatov $O$, Kim TY, Cunningham $D$, Rougier $P$, Komatsu $Y$, Ajani $J$ Emig $M$, Carlesi $R$, Ferry $D$, Chandrawansa $K$ Schwartz JD, Ohtsu A (2014) Ramucirumab plus paclitaxel versus placebo plus paclitaxel in patients with previously treated advanced gastric or gastro-oesophageal junction adenocarcinoma (RAINBOW): a double-blind, randomised phase 3 trial. Lanco Oncol. 15: 1224-1235.

Wynes MW, Hinz TK, Gao D, Martini M, M arek LA, Ware KE Edwards MG, Bohm D, Perner S, Helfrich BA, Dziadziuszko R, Jassem d Wojtylak S, Sejda A, Gozgit M, Bunn PA t, Camidge DR, Tan AC, Hirsch FR, Heasley LE (2014) FGFRl $m R N A$ and protein expression, not gene copy number, predict FGFR TKI sensitivity across all lung cancer histologies. Clin. Canor Res 20: 3299-3309.

Yada T, Yokoi C, Uemura N (2013) The current state of diagnosis and treatment for early gastric cancer. Diagn. Ther. Endoos 2013: 241320: 1-9. 